\title{
MAGNETIC INDUCTION MACHINES EMBEDDED IN FUSION-BONDED SILICON
}

\author{
David P. Arnold*, Florent Cros, Iulica Zana, and Mark G. Allen \\ School of Electrical and Computer Engineering, Georgia Institute of Technology \\ Atlanta, GA 30332-0269 \\ Sauparna Das and Jeffrey H. Lang \\ Dept of Electrical Engineering \& Computer Science, Massachusetts Institute of Technology \\ Cambridge, MA 02139-4307
}

\begin{abstract}
This paper presents the design, fabrication, and characterization of laminated, magnetic induction machines intended for high-speed, high-temperature, high-power-density microengine power generation systems. Innovative fabrication techniques were used to embed electroplated materials $(\mathrm{Cu}$, $\left.\mathrm{Ni}_{80} \mathrm{Fe}_{20}, \mathrm{Co}_{65} \mathrm{Fe}_{18} \mathrm{Ni}_{17}\right)$ within etched and fusion-bonded silicon to form the machine structure. The induction machines were characterized in motoring mode using tethered rotors, and exhibited a maximum measured torque of $2.5 \mu \mathrm{N} \cdot \mathrm{m}$ and a projected torque density of $340 \mathrm{~N} \cdot \mathrm{m} / \mathrm{m}^{3}$.
\end{abstract}

\section{INTRODUCTION}

The power demands of modern electronic devices are quickly outpacing the energy and power density of today's best batteries. This has driven the development of new compact, electric power sources in the 10-100 watt range for use in portable electronics, remotely located sensors, and robotic devices. One potential system, is a microengine $[\mathbf{1 , 2}]$ - a small (few cubic centimeters) gas-fueled turbine engine $[\mathbf{3 , 4}]$ coupled to an electrical power generator [5-8]. Such a system has the potential to reduce the mass, life-cycle costs, and cumbersome logistics of conventional batteries while providing uninterrupted high density power.

Both electric $[\mathbf{5}, \mathbf{6}]$ and magnetic $[\mathbf{7 , 8}]$ induction machines have been investigated to convert the mechanical energy into electrical power, for use in a microengine. To achieve the desired power densities, the electrical generator must support high rotor spin $(\sim 1 \mathrm{Mrpm})$ and tip $(500 \mathrm{~m} / \mathrm{s})$ speeds. Also, for integration with the multi-wafer-bonded turbine microengines, the machine must withstand high operating temperatures $\left(\sim 300^{\circ} \mathrm{C}\right)$ and use a compatible fabrication process.

As compared to their electric counterparts, magnetic machines may offer higher power densities, higher efficiencies (e.g. lower windage losses), less stringent fabrication tolerances (e.g. larger air gap), and simpler power electronics. They also operate at lower voltages and higher currents and are therefore easier to integrate with typical electronic devices. The previously reported magnetic induction machines were fabricated using SU-8 micromolding and multi-level electroplating of various metals $[7,8]$. These first-generation devices successfully demonstrated electromechanical power conversion, but were not integrable with the silicon-based microturbines and were limited in temperature due to the presence of the SU-8 polymer. This paper extends the previous research by demonstrating silicon-based, wafer-bonded, high-temperature, laminated, magnetic induction machines. This represents another step towards fully-integrated power generators for silicon-based microengines.

*Travel support has been generously provided by the Transducers Research Foundation and by the DARPA MEMS and DARPA BioFlips programs.

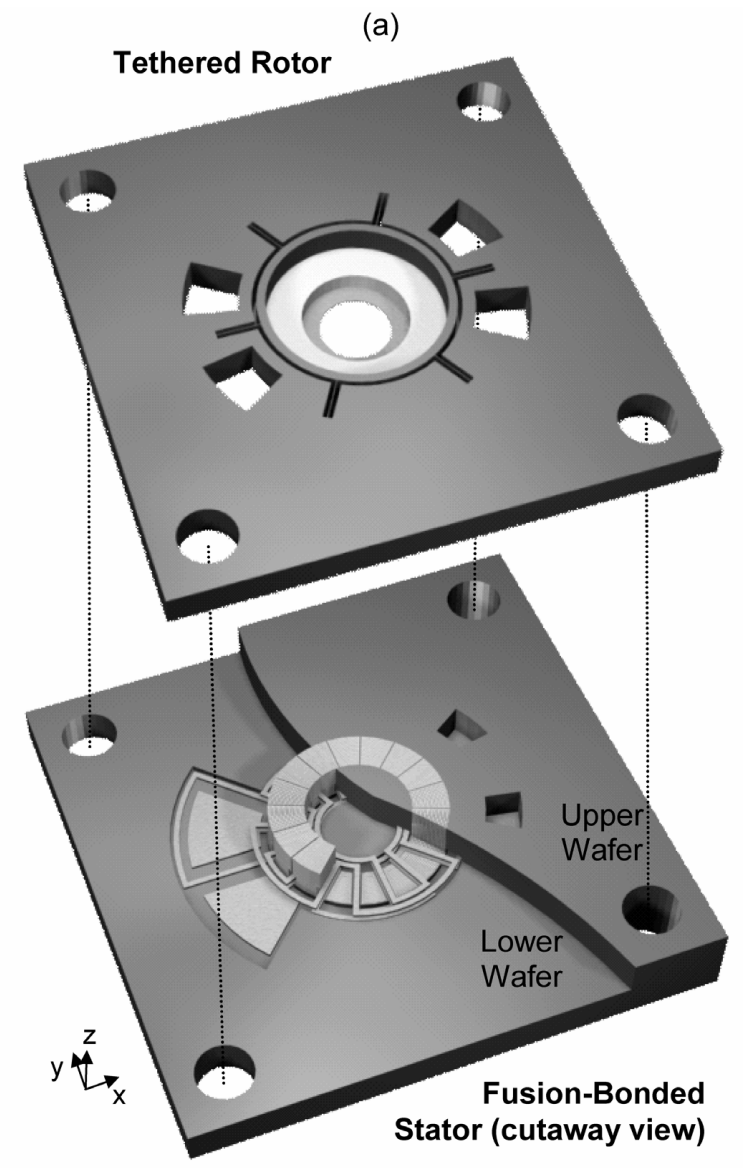

(b)

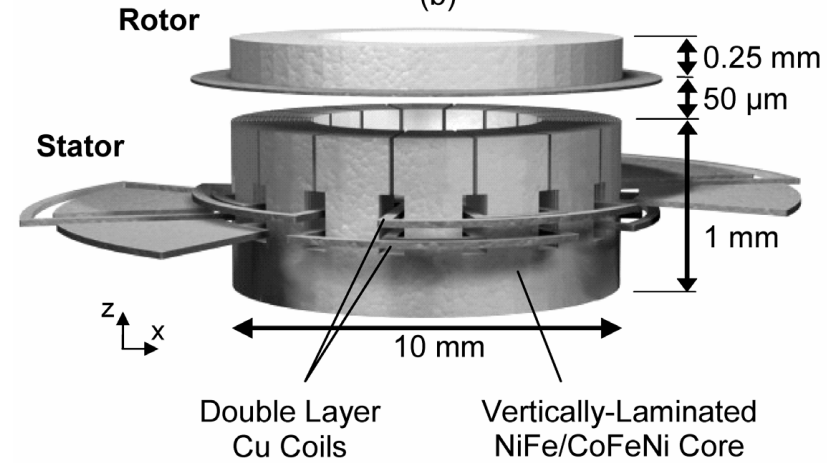

Figure 1. Renderings of the magnetic induction machine (z-axis expanded by $4 x$ and air gap exaggerated). (a) Perspective view, showing a cutaway of the machine components embedded within the bonded silicon. (b) Side view, showing only the magnetic rotor and stator core and phase windings. 


\section{INDUCTION MACHINE DESIGN}

The magnetic machine is designed for maximum power density and efficiency in the context of interoperability with a microturbine system. As a result, the design is constrained by system level compatibility issues and microfabrication limitations. First, the turbine-generator system is intended to operate with a 10 $\mathrm{mm}$ OD rotor spinning with a $500 \mathrm{~m} / \mathrm{s}$ tip speed. Second, to support the high currents and magnetic fluxes needed for high power density, the machine must have relatively large geometric dimensions ( $\sim \mathrm{mm})$. Finally, as mentioned previously, the machine should withstand operating temperatures of $\sim 300^{\circ} \mathrm{C}$ and be fabricated using silicon wafer-bond compatible processes.

Within these constraints, a planar induction machine was designed consisting of two primary components: a two-phase, 8pole stator and a composite annular rotor, as shown in Fig. 1. Electromechanical energy conversion occurs through the interaction of a traveling magnetic wave in the rotor-stator air gap and the eddy currents induced in the rotor by the traveling wave [9]. In motoring mode, a traveling magnetic wave is established by applying two currents in quadrature to the two stator phases, resulting in a torque on the rotor.

The stator contains two phases made up of planar $\mathrm{Cu}$ coils wound in a three-dimensional, vertically-laminated ferromagnetic core, all supported by a silicon frame. The core laminations form onion-like concentric rings, where the lamination thickness is approximately one skin depth $(\sim 30 \mu \mathrm{m})$ to limit eddy current losses [10]. The rotor is a $250 \mu \mathrm{m}$ thick ferromagnetic annular ring (10 $\mathrm{mm}$ OD, $6 \mathrm{~mm}$ ID) with a $20 \mu \mathrm{m}$ thick overlayer of $\mathrm{Cu}$. The $\mathrm{Cu}$ extends beyond the magnetic region ( $12 \mathrm{~mm} \mathrm{OD,} 4 \mathrm{~mm}$ ID) to enhance eddy current generation in the rotor for maximum torque. Machines were designed using either $\mathrm{Ni}_{80} \mathrm{Fe}_{20}$ or $\mathrm{Co}_{65} \mathrm{Fe}_{18} \mathrm{Ni}_{17}$ as the ferromagnetic material. As compared to $\mathrm{NiFe}$, the $\mathrm{CoFeNi}$ alloy has similar permeability and resistivity, but offers higher saturation flux density (higher power density) and higher Curie temperature (higher operating temperature) at the expense of a slight increase in coercivity (larger hysteresis loss) [11].

For testing purposes, the rotor was suspended above the stator using flexible silicon tethers that permitted angular rotation and a controllable air gap while avoiding the difficulties of supporting a spinning rotor. This simulates a blocked rotor test, commonly used to test macro-scale machines [9]. Six, $35 \mu \mathrm{m}$ wide, $475 \mu \mathrm{m}$ tall, $2.5 \mathrm{~mm}$ long silicon tethers were designed to provide an angular compliance of $25 \mathrm{rad} / \mathrm{N} \cdot \mathrm{m}$ with a stiffness in the axial direction of $4.2 \mu \mathrm{m} / \mathrm{N}$ to prevent rotor pull-in.

\section{DEVICE FABRICATION}

Innovative fabrication techniques were used to embed thick electroplated coils and cores within etched and wafer-bonded silicon to form the machine stators. The rotors and silicon tether structures were fabricated separately and assembled together for rapid prototyping with the stators.

Stators were fabricated by embedding coils inside of fusionbonded silicon wafers and then building the magnetic core around the coils as depicted by Fig. 2. The process began with two highly-doped $(\sim 0.001 \Omega \cdot \mathrm{cm})$, n-type, $100 \mathrm{~cm}$ double-side-polished silicon wafers. In each wafer, $70 \mu \mathrm{m}$ deep cavities were etched using deep reactive ion etching (DRIE) and a $200 \mathrm{~nm}$ thermal $\mathrm{SiO}_{2}$ layer was grown. Then, a $400 \mathrm{~nm}$ Ta diffusion barrier and $200 \mathrm{~nm}$ $\mathrm{Cu}$ seed layer were DC sputtered across the surfaces of the wafers. Next, a thick negative photoresist was patterned in the cavities to define a mold for the coils, maintaining a minimum clearance of 50 $\mu \mathrm{m}$ from the cavity sidewalls. Patterning the mold within the cavities permitted uniform plating and prevented protrusions, which would inhibit wafer bonding. After plating, the photoresist, metallic seed layers, and $\mathrm{SiO}_{2}$ were wet-etched back down to the pristine silicon surface, leaving the coil recessed in the cavity as shown in Fig. 3. The two wafers were then aligned and fusion bonded, sealing the coils inside. The bonding was performed at $500^{\circ} \mathrm{C}$ for 4 hours under vacuum $\left(<2 \times 10^{-6}\right.$ torr $)$ with $200 \mathrm{kPa}$ clamping pressure, resulting in a strong, uniform bond without degrading the embedded copper as reported in [11]. Next, a $3 \mu \mathrm{m}$ PECVD oxide was deposited on the top and bottom surfaces of the bonded pair. Using this oxide layer and photoresist as masks, nested etches were performed from the bottom and top sides to form a silicon skeleton for the laminated core. Then, using a method detailed in [12], $\sim 30 \mu \mathrm{m}$ of $\mathrm{NiFe}$ or $\mathrm{CoFeNi}$ was selectively electroplated onto the conductive silicon sidewalls to form the magnetic laminations. The metals plated only on the etched silicon regions, with the $\mathrm{SiO}_{2}$ layer on the top and bottom surfaces acting as a mask. Finally, contact openings were made from the top side by etching the silicon down to the buried coil contacts. Fig. 4 shows images of the completed stator.

The tethered rotor structures were built by assembling metallic rotors into tethered silicon rings. Rotors were built on a silicon substrate by first electroplating a $250 \mu \mathrm{m}$ thick NiFe or $\mathrm{CoFeNi}$ annular ring on top of a $20 \mu \mathrm{m}$ thick $\mathrm{Cu}$ ring using SU-8

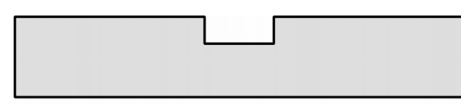

Etch trench for coil

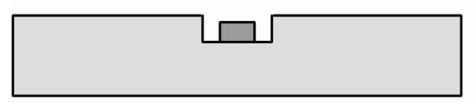

Plate coil in trench

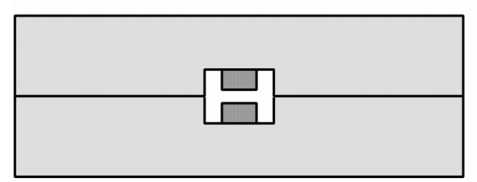

Fusion bond to second identical wafer

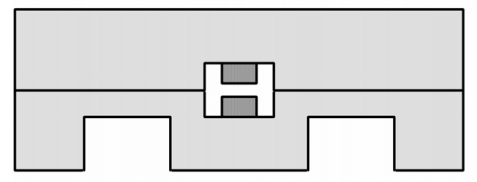

First etch on backside (pole)

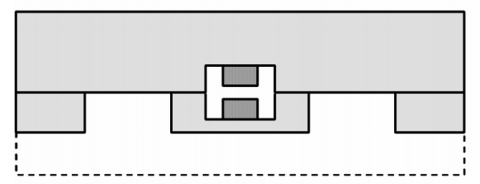

Second etch on backside (backiron)

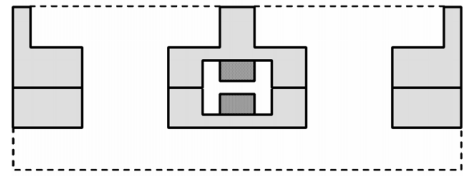

First and second etches on topside (pole/hat)

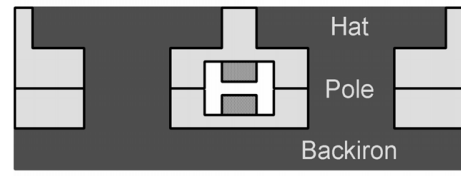

Plate core laminations on silicon sidewalls

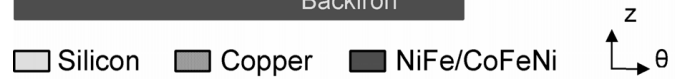

Figure 2. Simplified fabrication process flow for wafer-bonded machine stator, depicting cross sections in $\theta-z$ plane: two coil conductors pass radially through the laminated core structure (laminations not shown). 
(a)

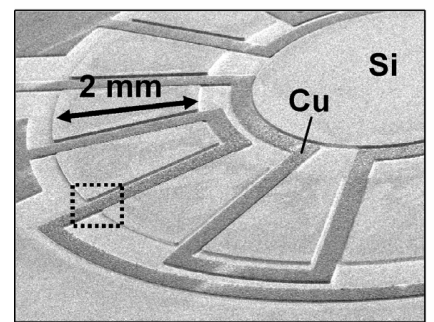

(b)

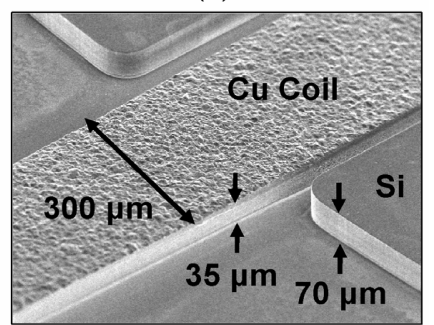

Figure 3. (a) SEM of $35 \mu \mathrm{m}$ thick, $300 \mu \mathrm{m}$ wide, copper coil recessed in $70 \mu \mathrm{m}$ deep silicon cavity before wafer bonding to a second identical wafer; (b) Detail. (a)

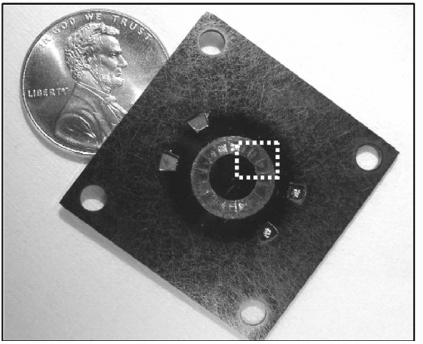

(b)

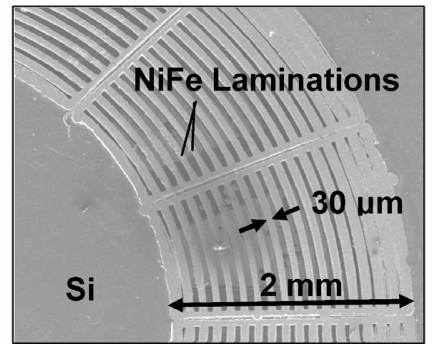

Figure 4. (a) Fabricated wafer-bonded machine stator; (b) SEM of highlighted region showing $30 \mu \mathrm{m}$ wide, $1000 \mu \mathrm{m}$ tall, NiFe vertical magnetic laminations.

molds. The SU-8 was then removed and the silicon substrate was etched away using $\mathrm{KOH}$. The silicon tether structures were formed separately by through-etching a wafer using DRIE. The rotors were subsequently glued into the tethered retaining ring.

\section{CHARACTERIZATION}

For characterization, the rotor was suspended above the stator with flexible silicon tethers to avoid the difficulties of supporting and stabilizing a spinning rotor. The stator and tethered rotor components were clamped together and mounted on a watercooled chuck as shown in Fig. 5. An air gap of $50 \mu \mathrm{m}$ was maintained between the stator and rotor by using Kapton spacers.

Power electronics supplied a balanced current excitation in quadrature to the stator phases. The drive signals were routed through a circuit that could swap the phases at a given frequency (the torque reversal frequency) to control the direction of the traveling magnetic wave and resulting torque. Using this setup, the

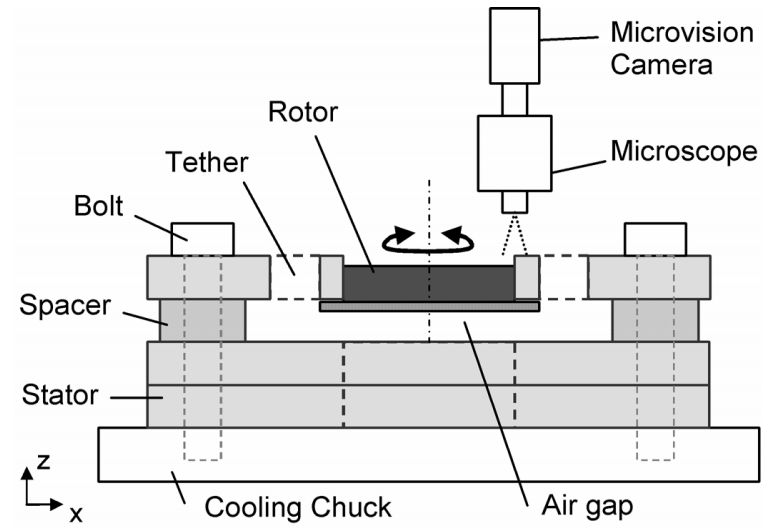

Figure 5. Schematic of the measurement setup showing the tethered rotor structure clamped to the stator on the cooling chuck. The air gap was maintained at $50 \mu \mathrm{m}$. tethered rotor was excited at a torque reversal frequency much lower than the electrical frequency. A microvision image analysis system was used to dynamically measure the angular deflection of the tethered rotor under the influence of the oscillating torque input, as described in [8]. The torque was extracted by fitting a second-order response $T=J \ddot{\theta}+b \dot{\theta}+k \theta$ to the measured data.

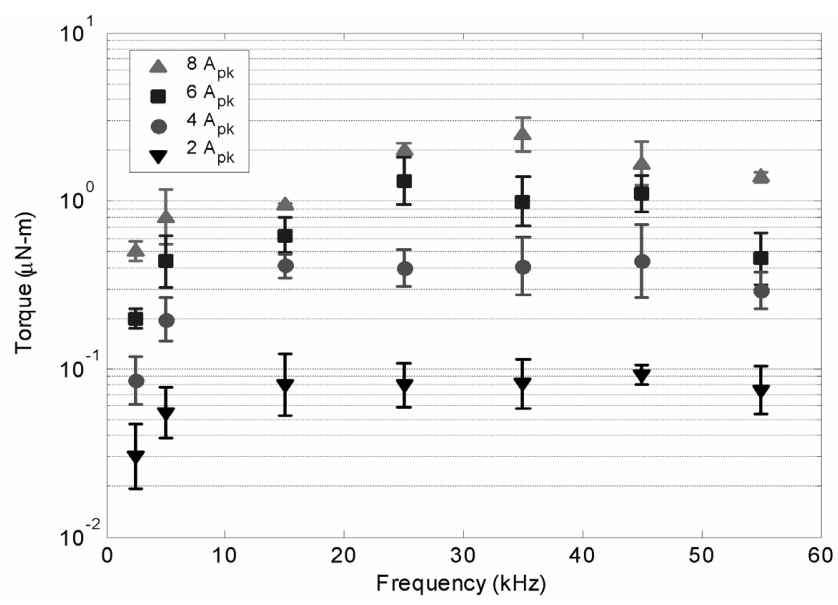

Figure 6. NiFe machine measured torque vs. electrical frequency for currents of $2-8 A_{p k}$ with $50 \mu$ m air gap.

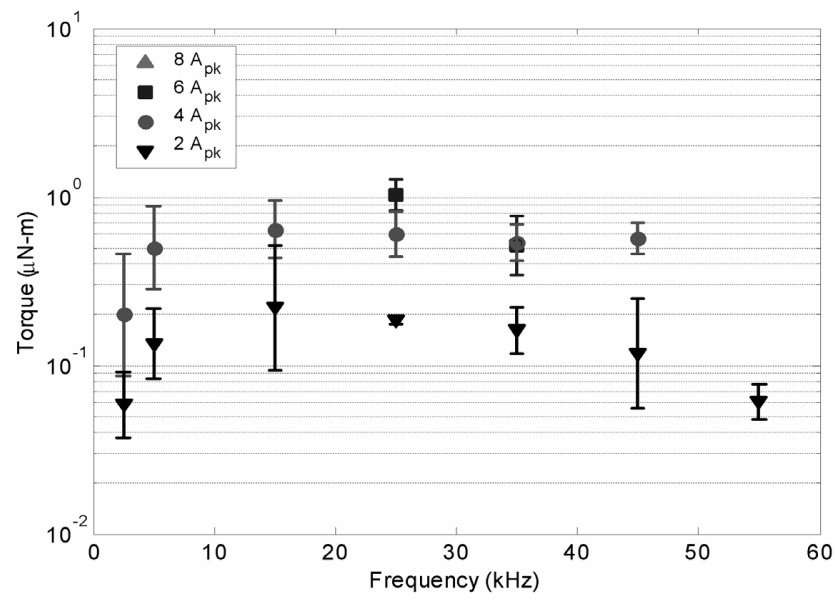

Figure 7. CoFeNi machine measured torque vs. electrical frequency for currents of $2-6 A_{p k}$ with $50 \mu \mathrm{m}$ air gap.

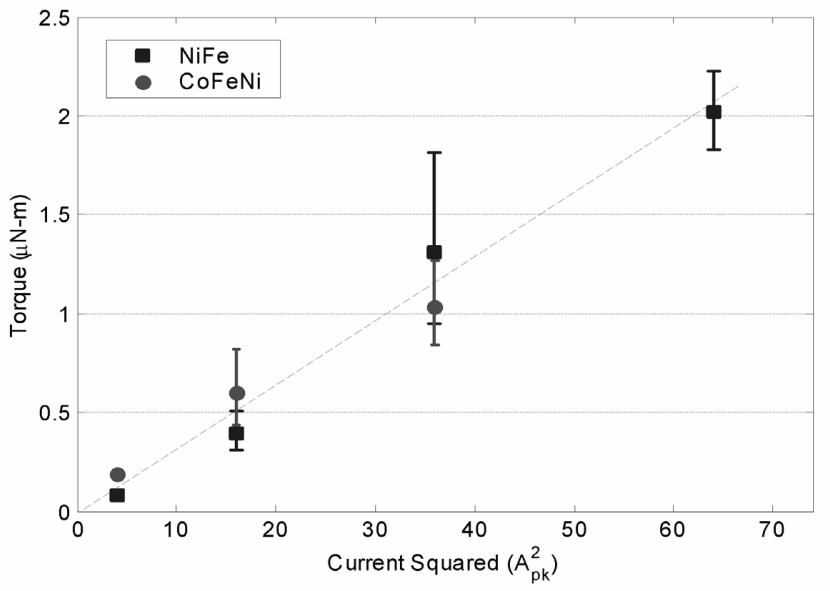

Figure 8. Torque vs. square of stator current for NiFe and CoFeNi machines at $25 \mathrm{kHz}$ with 50 um air gap. 
Machines were analyzed in motoring mode by varying both the amplitude and frequency of the excitation currents. The machines show characteristic induction machine behavior as shown in Figs. 6 and 7 . The error bars indicate 95\% confidence intervals, based on the accuracy of the curve fit to the dynamic response data. The tethered motor testing was limited to a maximum of $8 \mathrm{~A}_{\mathrm{pk}}$ (approximately $8 \mathrm{~W}$ per phase, for $0.25 \Omega$ coil resistance) because the displacement of the rotor became nonlinear and out-of-plane motion was detected, both causing large uncertainties in the torque extraction.

The NiFe machine shows a maximum torque of $2.5 \mu \mathrm{N} \cdot \mathrm{m}$ at $8 \mathrm{~A}_{\mathrm{pk}}, 35 \mathrm{kHz}$. Tests of the CoFeNi machine were corrupted at high currents by broken tethers, and only two data points were collected above $4 \mathrm{~A}_{\mathrm{pk}}$. Regardless, the CoFeNi machine demonstrated $1.0 \mu \mathrm{N} \cdot \mathrm{m}$ at $6 \mathrm{~A}_{\mathrm{pk}}, 25 \mathrm{kHz}$. At low currents, where no magnetic saturation occurs, the torque should show a quadratic dependence with current; upon saturation, the torque should increase linearly. Fig. 8 plots the torque vs. the square of current. The data follows this quadratic relation, indicating that neither machine had saturated, and that higher currents may be used to achieve even larger torques. While not measured, the machine should support currents of at least $32 \mathrm{~A}_{\mathrm{pk}}$ (corresponding to a current density of $3 \times 10^{9} \mathrm{~A} / \mathrm{m}^{2}$ ). At this level, and assuming no saturation, the machine would exhibit $\sim 40 \mu \mathrm{N} \cdot \mathrm{m}$ of torque (340 $\mathrm{N} \cdot \mathrm{m} / \mathrm{m}^{3}$ torque density).

\section{CONCLUSIONS \& FUTURE WORK}

These successful demonstrations of laminated, waferbonded, Si-based magnetic machines represent progress toward a fully-integrated microengine system. The materials, structure, and fabrication processes offer the potential for higher operating temperatures and direct integration with multi-wafer microturbine devices.

The performance of these silicon-based machines is comparable to the previously reported SU-8-based machine [8] as summarized in Table 1 . Torque density normalizes the torque by the active volume of the machine. The average surface shear stress normalizes the torque generated on the surface of the rotor by surface area and moment arm. This is the average force per unit area generated in the rotor by the electromechanical interactions. Although higher torque densities and shear stresses have been reported for electric induction machines $[7,8]$, those results were obtained using spinning, not tethered rotors.

\begin{tabular}{|l|c|c|c|c|c|c|}
\hline Device & $\begin{array}{c}\mathrm{a} \\
(\mathrm{mm})\end{array}$ & $\begin{array}{c}\mathrm{b} \\
(\mathrm{mm})\end{array}$ & $\begin{array}{c}\mathrm{t} \\
(\mathrm{mm})\end{array}$ & $\begin{array}{c}\text { Max. } \\
\text { Torque } \\
(\mu \mathrm{N} \cdot \mathrm{m})\end{array}$ & $\begin{array}{c}\text { Torque } \\
\text { Density } \\
\left(\mathrm{N} \cdot \mathrm{m} / \mathrm{m}^{3}\right)\end{array}$ & $\begin{array}{c}\text { Shear } \\
\text { Stress } \\
\left(\mathrm{N} / \mathrm{m}^{2}\right)\end{array}$ \\
\hline $\begin{array}{l}\text { Magnetic } \\
\text { SU-8-based [8] }\end{array}$ & 1.0 & 2.0 & 2.0 & 0.3 & 12 & 20 \\
\hline $\begin{array}{l}\text { Magnetic } \\
\text { Si-based }\end{array}$ & 3.0 & 5.0 & 1.5 & 2.5 & 21 & 12 \\
\hline
\end{tabular}

Table 1. Comparison of magnetic induction machine measured performances ( $a, b$, and t are the inner radius, outer radius, and thickness, respectively, for the active machine volume-stator, rotor, and air gap, excluding the windings).

It is believed that the performances of the machines reported here are limited by two fabrication issues. First, the teeth gaps between adjacent poles on the upper surface of the stator core are partially closed over due to overplating of the laminations. This shorts out the magnetic flux path between the stator and rotor and limits torque production. Second, in using highly doped silicon for the stator frame, the eddy currents, which would normally be confined to small loops around each lamination, are now allowed to circulate around an entire stator pole. These large eddy current loops reduce the flux linking the stator and rotor and limit the effectiveness of the laminations. The defective teeth gaps may be repairable and the machines retested. Alternatively, rebuilding machines with a nonconductive stator frame, larger coils, and more aggressive fabrication could also further improve the torque.

Future efforts will focus on enabling spinning rotors for testing in both motoring and generating mode. This will permit measurements of speed, power, and efficiency for additional characterization.

\section{ACKNOWLEDGEMENTS}

This work was supported by the Army Research Laboratory (DAAD19-01-2-0010) and Army Research Office (DAAG55-981-0292). The authors thank the staff of the Microelectronics Research Center at Georgia Tech for their assistance with fabrication and Dr. D. Freeman's group at MIT for use of the computer microvision system.

\section{REFERENCES}

1. A. H. Epstein, S. D. Senturia, et al., "Power MEMS and microengines," Tech. Dig. Int. Conf. Solid-State Sensors and Actuators (Transducers '97), June 1997, pp. 753-756.

2. A. H. Epstein and S. D. Senturia, "Macro power from micro machinery;" Science, vol. 276, no. 5316, p. 1211, May 1997.

3. A. Mehra, et al., "A six-wafer combustion system for a silicon micro gas turbine engine," J. Microelectromech. Syst., vol. 9, pp. 517-27, 2000.

4. L. G. Frechette, et al., "Demonstration of a microfabricated high-speed turbine supported on gas bearings," Tech. Dig. SolidState Sensor and Actuator Workshop (Hilton Head 2000), June 2000, pp. 43-7.

5. L. G. Frechette, et al., "An electrostatic induction micromotor supported on gas-lubricated bearings," Tech. Dig. $14^{\text {th }}$ IEEE Int. Conf. MEMS (MEMS 2001), Jan. 2001, pp. 290-293.

6. C. Livermore, et al., "A high-power MEMS electric induction motor," Tech. Dig. Solid-State Sensor and Actuator Workshop (Hilton Head 2002), June 2002, pp. 251-254.

7. F. Cros, et al., "Micro-magnetic induction machines for portable power applications," Proc. Army Research Lab Collaborative Technology Alliances, Power and Energy, April 2003, pp. 17-21.

8. H. Koser, "Development of magnetic induction machines for micro turbo machinery," Ph.D. Thesis, Massachusetts Institute of Technology, Cambridge, MA, June 2002.

9. A.E. Fitzgerald, C. Kingsley, Jr., S. D. Umans, Electric Machinery, $6^{\text {th }}$ Ed., New York: McGraw Hill, 2002.

10. J. Lammeraner and M. Stafl, Eddy Current, London: Iliffe, ch. $1-2,1966$

11. R. M. Bozorth, Ferromagnetism, New York: IEEE Press, Reissue, pp.162-169, 1993.

12. D. P. Arnold, et al., "Electroplated metal microstructures embedded in fusion-bonded silicon: conductors and magnetic materials," J. Microelectromech. Syst., (submitted).

13. D. P. Arnold, et al., "Vertically-laminated magnetic cores by electroplating Ni-Fe into micromachined Si," IEEE Trans. Magn. (in publication). 